\title{
Keanekaragaman Lamun di Pesisir Pantai Molas, Kecamatan Bunaken Kota Manado \\ (Biodiversity of Seagrass on Molas Seashore in Bunaken Subdistrict, Manado)
}

\author{
Pience Veralyn Maabuat ${ }^{1)^{\star}}$, Julius Sampekalo ${ }^{2)}$, H.E.I. Simbala ${ }^{1)}$ \\ 1) Jurusan Biologi Fakultas MIPA Universitas Sam Ratulangi Manado \\ 2) Fakultas Perikanan dan IImu Kelautan Universitas Sam Ratulangi, Manado \\ *E-mail korespondensi:Thealyn@yahoo.com
}

Diterima 16 Januari 2012, diterima untuk dipublikasikan 2 Februari 2012

\begin{abstract}
Abstrak
Ekosistem lamun merupakan salah satu ekosistem bahari yang produktif. Selain sebagai sumber produktifitas primer di perairan, ekosistem lamun juga memiliki arti penting bagi hewan yang hidup di area padang lamun. Penelitian ini dilaksanakan di Pesisir Pantai Molas dengan menggunakan metode garis transek kuadrat, yang dilakukan pada bulan Januari - Juni 2011. Analisis data meliputi perhitungan dengan rumus Krebs dan Fachrul, identifikasi jenis lamun dan penentuan indeks keanekaragaman menggunakan Shannon Wiener. Ada lima jenis lamun yang ditemukan yaitu Enhalus acoroides, Thalassia hemprichii, Halophila ovalis, Cymodocea rotundata dan Syringodium isoetifolium. Lamun E. acoroides dan $S$. isoetifolium memiliki penyebaran terluas, karena ditemukan di seluruh transek pada lokasi penelitian. Jenis yang jarang dijumpai adalah $H$. ovalis. Jumlah individu yang ditemukan adalah 130 individu. Nilai indeks keanekaragaman di pesisir Pantai Molas memperlihatkan di wilayah ini keanekaragaman jenis lamun sedang dibandingkan 13 lokasi lainnya di Indonesia.

Kata kunci: biodiversitas, Molas, rumput laut
\end{abstract}

\begin{abstract}
Seagrass ecosystem is one of the productive marine ecosystems. This ecosystem is a source of primary productivity in waters and it is significant for the animals that live in the seagrass areas. This study was conducted in the Molas coastal using the method of transect line squares, in January-June 2011. The analysis included calculation using the formula of Krebs and Fachrul, identification of seagrass species and determination Shannon Wiener diversity index. Five species of seagrass species were found, i.e. Enhalus acoroides, Thalassia hemprichii, Halophila ovalis, Cymodocea rotundata and Syringodium isoetifolium. The total number of individual weres 130. Index value of diversity in the Molas coastal showed that the seagrass diversity in this region were medium compared with 13 other locations in Indonesia.
\end{abstract}

Key Words : biodiversity, Molas, seagrass

\section{PENDAHULUAN}

Ekosistem lamun merupakan salah satu ekosistem bahari yang produktif, selain sebagai sumber produktifitas primer di perairan juga memiliki arti penting bagi hewan yang hidup di area padang lamun, diantaranya menyediakan daerah perawatan (nursery area) bagi banyak spesies yang menyokong perikanan laut lepas, dan untuk habitat lainnya, seperti rawa payau, terumbu karang, dan hutan mangrove (Short dan Coles, 2003). Di wilayah perairan Indonesia tercatat ada 13 jenis lamun yang 
telah teridentifikasi (Kiswara, 1994 dalam Susetiono, 2004), di dunia ada 58 jenis lamun ( Kuo dan McComb, 1989 dalam Kiswara dan Winardi, 1999). Pada tahun 2007 ditemukan jenis Halophila sulawesii oleh John Kuo di Kepulauan Spermonde Sulawesi Selatan dan jenis ini masuk dalam daftar tumbuhan endemik. Hal ini menunjukkan bahwa di perairan Indonesia masih terkandung sumberdaya lamun yang belum tereksplorasi, sehingga perlu terus dilaksanakan pengkajian.

Penelitian yang sama menyangkut lamun, telah di dilaksanakan di wilayah Propinsi Sulawesi Utara seperti di pesisir Tongkaina oleh Peuru ( 2007) menemukan lima jenis, Blonko lima jenis ( Abdullah 1996), Selat Lembeh (Susetiono 2004) menemukan delapan jenis lamun, perairan Tanjung Merah Bitung (Takendengan (2007) tujuh jenis, di Kabupaten Minahasa Selatan (Durand 2008) delapan jenis, Pulau Talise (Takaendengan dan Azkab 2010) tujuh jenis, Perairan Tandurusa sebanyak 4 jenis, Mokupa 4 jenis, dan Boyong Pante 3 jenis (Peuru 2007).

Informasi ilmiah dari hasil pengkajian lamun merupakan hal yang penting, selain untuk menambah pengetahuan juga dapat dijadikan sebagai dasar pemikiran untuk pengambilan keputusan dalam melaksanakan suatu langkah konservasi jenis. Sedikitnya informasi dan kurangnya kepedulian akan mempengaruhi keberadaan suatu spesies bahkan ekosistem yang ada. Salah satu wilayah di Kota Manado yang masih kurang informasinya adalah pesisir pantai Molas, Kecamatan Bunaken. Tujuan penelitian ini ialah untuk mengidentifikasi jenis lamun yang tumbuh di Pesisir Pantai Molas, menganalisis kerapatan, frekuensi, penutupan dan Indeks Nilai Penting
(INP) di Pesisir Pantai Molas,Kecamatan Bunaken, Kota Manado. Penelitian ini dilaksanakan di Pesisir Pantai Molas (Gambar 1) Waktu penelitian dilaksanakan pada bulan Januari - Juni 2011 dengan memperhatikan waktu surut terendah.

\section{METODE}

Metode yang digunakan pada penelitian ini adalah metode line transek kuadrat $1 \times 1$ meter dengan pengambilan sampel dilakukan secara acak (Random sampling) mengacu pada Krebs (1989) dan Fachrul (2007). Untuk substrat perairan, teknik pengambilan sampelnya mengacu pada Pinnot (1992). Lamun yang ditemukan dalam plot, diidentifikasi jenisnya dan dihitung jumlah tegakkannya dengan menggunakan kunci identifikasi menurut Den Hartog (1970), Philips dan Menez (1988) dalam Short dan Coles (2003), serta Azkab (2009). Analisis data yaitu identifikasi jenis lamun dilakukan secara insitu. Untuk mengetahui keanekaragaman digunakan perhitungan nilai kerapatan jenis dan kerapatan relatif, frekuensi dan frekuensi relatif, penutupan jenis dan penutupan relatif lamun, serta untuk menduga keseluruhan dari peranan suatu jenis lamun dilakukan dengan perhitungan Indeks Nilai Penting (INP) mengacu pada Fachrul (2007). Untuk indeks keanekaragaman, karena data yang diambil pada penelitian ini secara acak maka menggunakan indeks ShannonWienner (Magurran 1988).

\section{HASIL DAN PEMBAHASAN}

Berdasarkan hasil pengukuran faktor fisika-kimia lingkungan perairan, suhu pada saat pengambilan data lamun di Pantai Molas berkisar $30-32^{\circ} \mathrm{C}$. Tertinggi di transek tiga yaitu $30-32^{\circ} \mathrm{C}$, terendah di transek 1 yaitu $30^{\circ} \mathrm{C}$. 


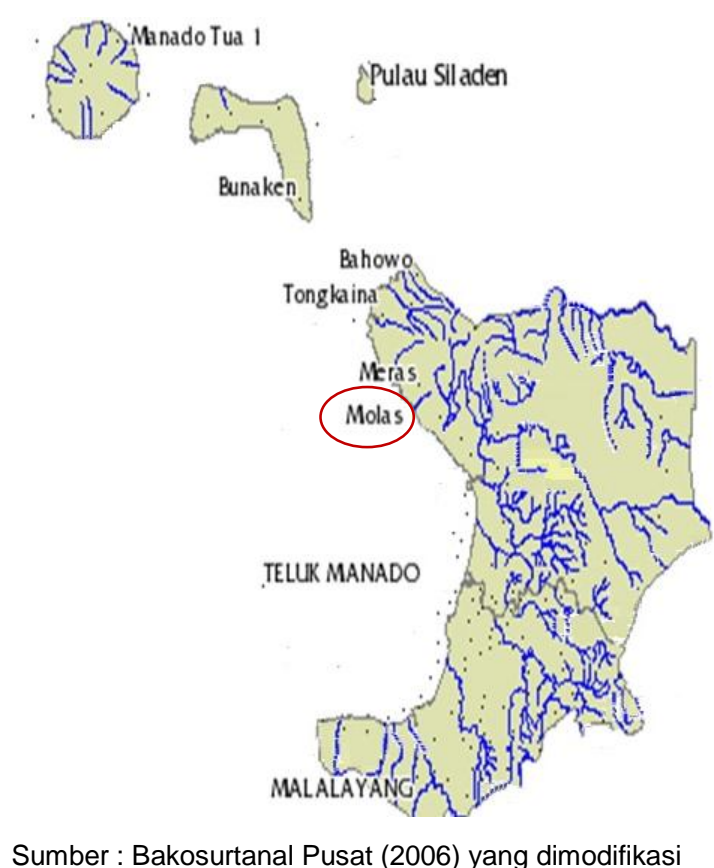

Gambar 1. Lokasi Penelitian

Pada transek 3 plot 5 yang memiliki suhu mencapai $32^{\circ} \mathrm{C}$, tidak ditemukan lamun. Oksigen terlarut (DO) di Pantai Molas berkisar 5.70 - $5.72 \mathrm{mg} / \mathrm{l}$, tertinggi di transek satu yaitu 5,71-5,72 $\mathrm{mg} / \mathrm{l}$, sedangkan terendah di transek dua yaitu 5,70 $5,71 \mathrm{mg} / \mathrm{l} . \mathrm{pH}$ di lokasi penelitian Pantai Molas berkisar 7,40-7,50, tertinggi di transek satu yaitu 7,46 7,50 dan terendah transek tiga yaitu 7,40-7,45. Salinitas di lokasi penelitian berkisar antara 31,0$33,70 \%$. Pantai Molas berkisar $31,0-33,1 \%$, tertinggi di transek satu yaitu $32,0-33,1 \%$, sedangkan terendah di transek tiga yaitu 31,0$32,0 \%$. Kecerahan pada lokasi penelitian Pantai Molas berkisar $0,12-0,52 \mathrm{~m}$, tertinggi di transek satu yaitu $0,25-0,52 \mathrm{~m}$, sedangkan terendah di transek tiga yaitu 0,12 $0,47 \mathrm{~m}$. Pantai Molas memiliki komposisi pasir halus tertinggi yaitu $33,69 \%$, terendah adalah debu $2,46 \%$.

Pada lokasi ditemukan lima jenis lamun yang tersebar di pesisir pantai MolasJenis lamun yang ditemukan masuk dalam dua famili yaitu Hydrocharitaceae dan Cymodoceaceae. Termasuk famili Hydrocharitaceae adalah Enhalus acoroides (Linnaeus f.) Royle, Thalassia hemprichii (Ehrenberg) Ascherson, dan Halophila ovalis (R.Brown) Hooker f. Famili Cymodoceaceae yaitu Cymodocea rotundata (Ehrenberg \& Hemprich) ex Ascherson dan Syringodium isoetifolium (Ascherson) Dandy. Jenis yang memiliki penyebaran terluas adalah $E$. acoroides dan $S$. isoetifolium. Dua jenis lamun tersebut ditemukan tersebar pada seluruh transek di lokasi penelitian. Jenis yang jarang ditemukan adalah $H$. ovalis. Jenis lamun yang ditemukan merupakan jenis yang secara umum ditemukan pada perairan tropis namun tidak ada jenis yang masuk kategori endemik.

1. E. acoroides (Linnaeus f.) Royle Daun berdiri tegak, panjang dan seperti pita, memiliki 2-5 helai yang menyerupai pita dengan panjang berkisar 12-30,2 cm sedangkan lebar kisaran 1,3-1,5 cm. Pada rimpang terdapat akar- akar 


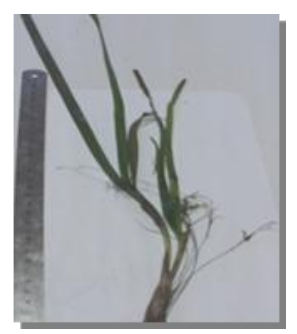

a

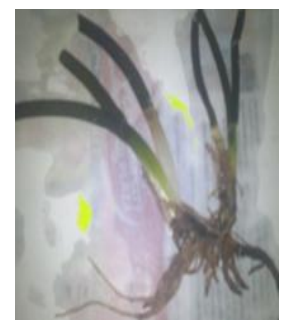

d

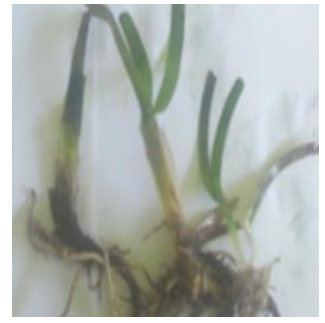

b

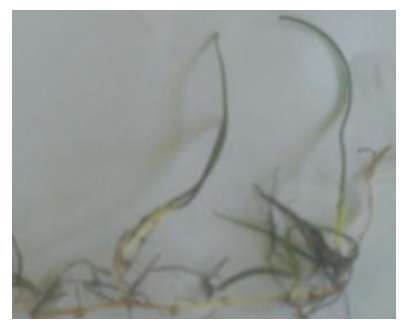

e

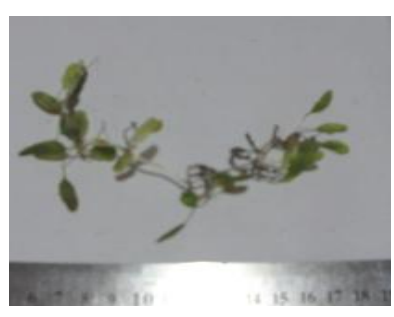

C

Gambar 2.Jenis Lamun di Pesisir Pantai Molas (a. E. acoroides,

b. T. Hemprichii, c. H. ovalis, d. C. rotundata, e. S. isoetifolium

yang banyak. Pada saat pengamatan tidak ditemukan bunga, buah dan biji (Gambar 2a).

\section{T. Hemprichii (Ehrenberg) Ascherson \\ Nama lokal galamu sama} seperti empat jenis lainnya, daunnya berbentuk lurus sampai melengkung seperti pita, tepian daun tidak menonjol atau rata dan ujung daun agak tumpul, panjang $5-10 \mathrm{~cm}$. Lebar daun $1 \mathrm{~cm}$, memiliki rimpang yang keras tanpa rambut-rambut kaku (Gambar 2b).

\section{Halophila ovalis (R.Brown) Hooker}

Daun berbentuk oval dengan tangkai daun, panjang 1-4 cm, dan garis-garis tulang daun jelas terlihat sebanyak 10-25 pasang (Gambar 2c).

4. Cymodocea rotundata

(Ehrenberg \& Hemprich) ex

Ascherson

Lamun yang memiliki ujung daun halus dan licin, pertulangan daun 9-15. Daun melengkung dan tidak mengecil ke arah bagian ujungnya. Panjang daun 5-7 cm, lebar 1,5 - $3 \mathrm{~cm}$ (Gambar 2d).
5. Syringodium

\section{(Ascherson) Dandy}

Memiliki daun pipih, bulat seperti lidi dengan ujung meruncing. Tumbuhan kecil atau berukuran pendek, daun berbentuk silindris dan agak panjang berkisar 7-12 cm (Gambar 2e).

Penelitian sebelumnya oleh Peuru (2007) menemukan 5 jenis di pesisir Tongkaina dan Blonko yaitu 5 jenis ( Abdullah 1996), masih lebih sedikit dibandingkan di Selat Lembeh (Susetiono 2004) telah menemukan delapan jenis lamun yaitu $E$. acoroides, $T$. hemprichii, $C$. rotundata, C. serrulata, $S$. isoetifolium, $H$. ovalis, Halodule pinifolia, dan Ha. Unninervis, sedangkan di Perairan Tanjung Merah Bitung oleh Takendengan (2007) menemukan tujuh jenis yaitu $E$. acoroides, $T$. hemprichii, $C$. rotundata, $S$. isoetifolium, $\mathrm{H}$. ovalis, Halodule pinifolia, dan $\mathrm{Ha}$. Unninervis.

ovalis, Halodule pinifolia, dan $\mathrm{Ha}$. Unninervis. Jika dibandingkan dengan hasil yang diperoleh di lokasi penelitian, jenis lamun yang ditemukan lebih sedikit, akan tetapi 


\section{JURNAL BIOSLOGOS, FEBRUARI 2012, VOL. 2 NOMOR 1}

keanekararagamannya masih lebih tinggi dibandingkan dengan yang ditemukan oleh Peuru (2007) di Perairan Tandurusa sebanyak 4 jenis, Mokupa yaitu 4 jenis, Boyong Pante yaitu 3 jenis.

Hasil analisis data lamun jenis S. isoetifolium memiliki nilai kerapatan tertinggi yaitu 82 individu $/ \mathrm{m}^{2}$ dengan kerapatan relatif $63,08 \%$, terendah adalah $T$. hemprichii yaitu 4 individu $/ \mathrm{m}^{2}$ dengan kerapatan relatif $3,08 \%$.
Berbeda dengan nilai kerapatan, frekuensi kehadiran E. acoroides lebih tinggi yaitu 0,53 dengan frekuensi relatif $40 \%$, dan terendah adalah $H$. ovalis yaitu 0,07 dengan nilai frekuensi relatifnya $5 \%$. Penutupan dan INP tertinggi diwakili oleh $S$. isoetifolium yaitu berturutturut $63,08 \%$ dan $156,15 \%$. Lamun T. hemprichii memiliki nilai penutupan dan INP terendah dibanding empat jenis lainnya yaitu $3,08 \%$ dan $16,15 \%$ (Tabel 1 ).

Tabel 1. Kerapatan, Frekuensi, Penutupan dan INP Lamun di Molas

\begin{tabular}{|c|c|c|c|c|c|c|c|c|}
\hline No & Jenis Lamun & $\mathrm{K}$ & $\begin{array}{l}\mathrm{KR} \\
(\%)\end{array}$ & $\mathrm{F}$ & FR $(\%)$ & $\mathrm{P}$ & PR (\%) & INP \\
\hline & Hydrocharitaceae & & & & & & & \\
\hline 1 & Enhalus acoroides & 25 & 19,23 & 0,53 & 40,00 & 6,25 & 19,23 & 78,46 \\
\hline 2 & Halophila ovalis & 8 & 6,15 & 0,07 & 5,00 & 2,00 & 6,15 & 17,31 \\
\hline \multirow[t]{2}{*}{3} & Thalassia hemprichii & 4 & 3,08 & 0,13 & 10,00 & 1,00 & 3,08 & 16,15 \\
\hline & Cymodoceaceae & & & & & & & \\
\hline 1 & $\begin{array}{l}\text { Cymodocea rotundata } \\
\text { Syringodium }\end{array}$ & 11 & 8,46 & 0,20 & 15,00 & 2,75 & 8,46 & 31,92 \\
\hline \multirow[t]{2}{*}{2} & isoetifolium & 82 & 63,08 & 0,40 & 30,00 & 20,50 & 63,08 & 156,15 \\
\hline & Total & 130 & 100,00 & 1,33 & 100,00 & 32,50 & 100,00 & 300,00 \\
\hline
\end{tabular}

Keterangan : $\mathrm{K}=$ Kerapatan, $\mathrm{KR}=$ Kerapatan Relatif, $\mathrm{F}=$ Frekuensi, FR = Frekuensi Relatif, $\mathrm{P}=$ Penutupan, $\mathrm{PR}=$ Penutupan Relatif, INP = Indeks Nilai Penting

Tabel 2. Indeks Keanekaragaman Lamun di Molas

\begin{tabular}{llccccc}
\hline \multirow{2}{*}{ No } & \multicolumn{1}{c}{ Jenis Lamun } & Jumlah & $\mathrm{Ni}$ & $\mathrm{pi}$ & $\ln \mathrm{Pi}$ & $\mathrm{Pi} \ln \mathrm{Pi}$ \\
& & & & & & \\
\hline 1 & Enhalus acoroides & 25 & 25 & 0,19 & $-1,66$ & $-0,32$ \\
2 & Halophila ovalis & 8 & 8 & 0,06 & $-2,81$ & $-0,17$ \\
3 & Cymodocea rotundata & 11 & 11 & 0,08 & $-2,53$ & $-0,20$ \\
4 & Thalassia hemprichii & 4 & 4 & 0,03 & $-3,51$ & $-0,11$ \\
5 & Syringodium isoetifolium & 82 & 82 & 0,63 & $-0,46$ & $-0,29$ \\
\hline & & $\mathrm{N}=130$ & 1,00 & & $-1,09$ \\
\hline & & & & $\mathrm{H}^{\prime}=$ & 1,09 \\
\hline
\end{tabular}

Ket $: \mathrm{ni}=$ jumlah individu suatu jenis, $\mathrm{pi}=$ jumlah total individu seluruh jenis 
Hasil analisis keanekaragaman lamun dengan menggunakan indeks keanekaragaman Shannon-Wienner seperti yang ditunjukkan pada tabel 2 diatas, menurut Magurran (1988) tergolong sedang karena nilai $H^{\prime}=1$ $\leq H^{\prime} \leq 3$ yaitu 1,09 .

Secara umum hasil yang diperoleh di lokasi penelitian seperti kerapatan sampai keanekaragaman, jenis $S$. isoetifolium mewakili jumlah individu tertinggi. Histogram di bawah (Gambar 2) , menunjukkan bahwa jumlah individu lamun di setiap transek juga bervariasi. Di di Pantai Molas jumlah individu $S$. isoetifolium tertinggi di transek 2 yaitu 41 individu dan terendah di transek 1 yaitu 16 individu. Jenis $E$. acoroides tertinggi di transek 2 yaitu 12 individu dan terendah 4 individu di tansek 1 , diikuti oleh $C$. rotundata tertinggi di Molas 6 individu, sedangkan $T$. hemprichii hanya ditemukan di transek 1 dan 2 yaitu masing-masing 2 individu. Tidak jauh berbeda dengan $H$. ovalis meskipun memiliki jumlah lebih banyak dari $T$. hemprichii, namun hanya ditemukan pada transek 2 saja.

Nilai kerapatan terendah ada di transek 1 yaitu 2-16 individu $/ \mathrm{m}^{2}$, dan tertinggi di transek 2 yaitu 2-41 individu $/ \mathrm{m}^{2}$. Apabila dihubungkan dengan letak lokasi yang lebih mendekati pusat kota dan berada dekat pemukiman penduduk, tentunya aktivitas manusia lebih tinggi. Transek 1 ini berdekatan dengan tempat wisata Baracuda, nampak dari beberapa kali pengamatan aktivitas manusia ramai di lokasi ini, baik datang dengan tujuan rekreasi, atau nelayan menjadikan tempat ini sebagai tambatan perahu untuk mencari ikan dan mengantar wisatawan yang datang. Aktivitas manusia tersebut diduga ikut mempengaruhi keberadaan lamun di lokasi ini. Kerapatan tertinggi di Molas di transek 2, meskipun berada didalam kawasan pemukiman, namun aktivitas masyarakat telah dibatasi untuk masuk ke lokasi ini karena merupakan milik pribadi. Pada transek 3 , didapati menjadi tempat keluar masuknya masyarakat yang berprofesi sebagai nelayan, serta menjadi tempat tambatan perahu.

Vegetasi padang lamun yang ada di lokasi ini tersusun atas 1-3 jenis, jenis $E$. acoroides merupakan jenis lamun yang cenderung membentuk vegetasi tunggal, yang kadang dijumpai bersama dengan $S$. isoetifolium dan yang membentuk asosiasi tiga jenis terdiri dari $E$. acoroides, T. hemprichii, dan $S$. isoetifolium. Menurut Holmlud et al. (1990) dalam Susetiono (2004) semakin padat vegetasi padang lamun akan semakin menguntungkan bagi beberapa hewan dari serangan pemangsa (predator) untuk melakukan deteksi, pengejaran dan menangkap mangsa menjadi lebih rendah.

Kurangnya pengetahuan masyarakat tentang arti penting ekosistem ini, selain itu pemerintah setempat dan instansi terkait masih kurang melakukan monitoring di pesisir Pantai Molas, Meras dan Bahowo, dapat menjadi sumber pelanggaran terhadap aturan yang sebelumnya telah ada, terutama terkait peraturan daerah perlindungan laut dan batasan untuk zona pariwisata. 


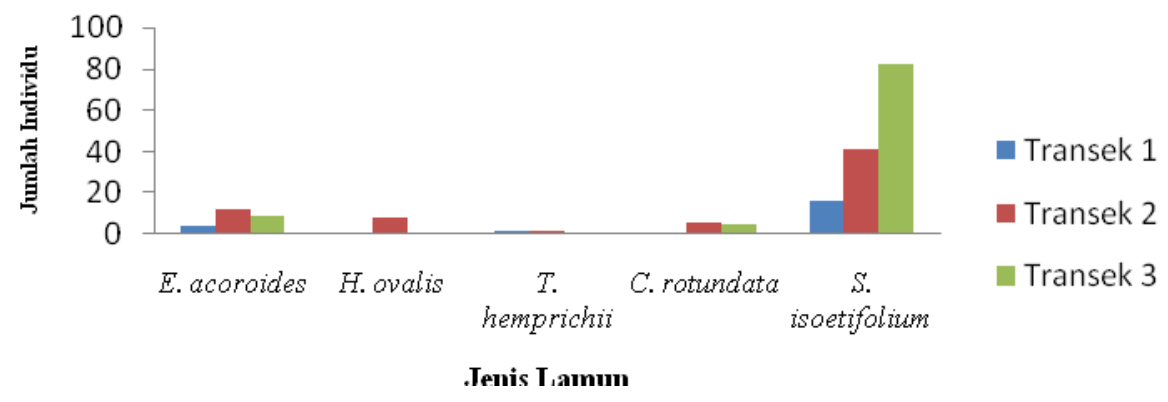

Gambar 2. Jumlah Individu Lamun di Molas

\begin{abstract}
Penerapan peraturan yang benar-benar terealisasi perlu diadakan di masa yang akan datang, melalui kegiatan monitoring pada lokasi pesisir ini oleh pemerintah dan instansi terkait di wilayah ini, sehingga dapat meminimalisir gangguan pada ekosistem padang lamun.
\end{abstract}

\section{KESIMPULAN}

Ada lima jenis lamun yang telah ditemukan di pesisir pantai Molas. Jenis yang ditemukan yaitu dari famili Hydrocharitaceae yaitu Enhalus acoroides, Thalassia hemprichii, dan Halophila ovalis. Famili Cymodoceaceae yaitu Cymodocea rotundata dan Syringodium isoetifolium. vegetasi lamun di Pesisir Pantai Molas didominasi oleh jenis $S$. Isoetifolium. Hasil analisis data lamun jenis $S$. isoetifolium memiliki nilai kerapatan tertinggi yaitu 82 individu $/ \mathrm{m}^{2}$ dengan kerapatan relatif $63,08 \%$, terendah adalah $T$. hemprichii yaitu 4 individu $/ \mathrm{m}^{2}$ dengan kerapatan relatif $3,08 \%$. Berbeda dengan nilai kerapatan, frekuensi kehadiran $E$. acoroides lebih tinggi yaitu 0,53 dengan frekuensi relatif $40 \%$, dan terendah adalah $\mathrm{H}$. ovalis yaitu 0,07 dengan nilai frekuensi relatifnya $5 \%$. Penutupan dan INP tertinggi diwakili oleh $S$. isoetifolium yaitu berturutturut $63,08 \%$ dan 156,15\%, sedangkan $T$. hemprichii terendah yaitu $3,08 \%$ dan 16,15\%. Indeks keanekaragaman pada tiga lokasi ini sedang dengan nilai 1.09 .

\section{DAFTAR PUSTAKA}

Abdullah RM (1996) Tinjauan tentang komunitas lamun laut (seagrass) di pesisir Pantai Tongkaina Kotamadya manado. Skripsi. Fakultas Perikanan Unsrat. Manado

Azkab MH (1999) Pedoman inventarisasi lamun. Oseana 24(1):1-16

Fachrul MF (2007) Metode sampling bioekologi. Edisi ke-2. Bumi Aksara, Jakarta.

Kiswara, W., Winardi (1999). Sebaran Lamun di Teluk Kuta dan teluk Gerupuk, Lombok Prosiding]. Pusat Penelitian Oseanografi-LIPI, Jakarta.

Kiswara W (1992) Vegetasi lamun (seagrass) di rataan terumbu Pulau Pari, Pulau-pulau Seribu, Jakarta. Oseanologi Indonesia 25:31-49

Krebs CJ (1989) Ecological methodology .Tapsco Inc, New York

Lintong, O (2010) Potensi ekowisata di kawasan pesisir ArakanWawontulap Propinsi Sulawesi Utara.Tesis. Program Pascasarjana Unsrat. Manado

Magurran AE (1988) Measuring biological diversity. Blackwell Publishing

Peuru G (2005) Studi morfologi lamun (seagrass) di pesisir perairan Semenanjung 
Minahasa dan sekitarnya. Tesis.

Program

Pascasarjana

Unsrat. Manado

Philips CR, EG Menez (1988)

Seagrass. Smith Sonian

Institutions Press, Washington DC

Pinnot PP (1992) Beberapa teknik yang lazim digunakan dalam penelitian geomorfologi dan penataan litoral (terjemahan G. Mamuaya)

Susetiono (2004) Fauna padang lamun Tanjung Merah Selat
Lembeh. Edisi ke-1. Pusat Penelitian OseanografiLIPI, Jakarta

Short FT, R Coles (2003) Global seagrass research method. Elsevier Science, Amsterdam

Takaendengan K (2007) Kajian ekonomi fauna yang berasosiasi dengan lamun di perairan Tanjung Merah Bitung Sulut. Tesis. Program Pascasarjana Unsrat. 